\title{
Vorwort des Bearbeiters der deutschen Ausgabe
}

Seit dem Erscheinen des Originalwerkes von Frau Professor Schtajerman im Jahre 1957 ist das Problem der Krise, die das Römische Reich nach der Mitte des 2. Jahrhunderts durchmachte, nicht zur Ruhe gekommen. Daher ergab sich die Notwendigkeit, für die deutsche Ausgabe einige neuere Literatur heranzuziehen. $\mathrm{Da}$ hierbei keine Vollständigkeit erreicht werden konnte, liegt bei dem Umfang des Gebietes auf der Hand. Außerdem wurden, soweit wie möglich, die Anmerkungen ergänzt und Zitate auf neuere Ausgaben umgestellt. Die umfangreiche Literatur, die die Verfasserin benutzt hat, war mir allerdings leider nicht vollständig zugänglich; daher war es nicht möglich, die Zitate ausnahmslos zu überprüfen.

Die Aufgabe, das Werk von Frau Schtajerman ins Deutsche zu übersetzen, habe ich mir in der Utberzeugung gestellt, daß die Förderung gegenseitigen Verstehens der sowjetischen und deutschen Altertumsforscher eine unbedingte Notwendigkeit ist. Außerdem hoffe ich gleichzeitig, mit der Herausgabe der deutschen Bearbeitung dieses Buches einen kleinen Beitrag zur Verständigung beider Völker überhaupt liefern zu können. Während der Arbeit des Utbersetzens war es mein Bestreben, die Gedankengänge der Verfasserin möglichst unverfälscht im Deutschen wiederzugeben, aber ich bin mir natürlich dessen bewußt, daß der Erreichung dieses Ziels gewisse Grenzen gesetzt sind. Eine abweichende Meinung habe ich nur in wenigen Fällen besonders angemerkt.

Wolfgang Seyfarth

Berlin, im Oktober 1963 